\title{
Fennel (Foeniculum Vulgare) Essential Oil as Green Corrosion Inhibitor of Carbon Steel in Hydrochloric Acid Solution
}

\author{
N. Lahhit, ${ }^{1}$ A. Bouyanzer, ${ }^{1}$ J.-M. Desjobert, ${ }^{2}$ B. Hammouti, ${ }^{1,}$ R. Salghi, ${ }^{3}$ \\ J. Costa, ${ }^{2}$ C. Jama, ${ }^{4}$ F. Bentiss ${ }^{5}$ and L. Majidi ${ }^{6}$ \\ ${ }^{1}$ LCAE-URAC18, Faculté des Sciences, Oujda, Morocco \\ ${ }^{2}$ UMR CNRS 6134, Lab. de Chimie des Produits Naturels, Université de Corse, France \\ ${ }^{3}$ E N S A, Equipe Génie de l'Environnement et de Biotechnologie, Agadir, Morocco \\ ${ }^{4}$ Université Lille Nord de France, F-59000 Lille, ENSCL, Unité Matériaux Et \\ Transformations UMET, UMR 8207, 59650 Villeneuve d'Ascq, France Cedex \\ ${ }^{5}$ LCCA, Faculté des Sciences, Université Chouaib Doukkali, B.P. 20, M-24000 El Jadida, \\ Morocco \\ ${ }^{6}$ Lab. des Subs. Nat. \& Synthèse et Dynamique Mol., F S T, Univ. My Ismail, Errachidia, \\ Morocco
}

\begin{abstract}
Essential oil from fennel (Foeniculum vulgare) (FM) was tested as corrosion inhibitor of carbon steel in $1 \mathrm{M} \mathrm{HCl}$ using electrochemical impedance spectroscopy (EIS), Tafel polarisation methods and weight loss measurements. The results show that the increase of the charge-transfer resistance $\left(R_{\mathrm{ct}}\right)$ with the oil concentration supports the molecules of oil adsorption on the metallic surface. The polarization plots reveal that the addition of natural oil shifts the cathodic and anodic branches towards lower currents. Such shifts indicate that FM oil acts as a mixed-type inhibitor. The global rate of corrosion estimated by weight loss measurements confirms the above results. The inhibition efficiency attains a maximum of $76 \%$ at $3 \mathrm{~mL} / \mathrm{L}$, but decreases with the rise of temperature. The analysis of FM oil, obtained by hydro-distillation, using Gas Chromatography (GC) and Gas Chromatography/Mass Spectrometry (GC/MS) showed that the major components were limonene $(20.8 \%)$ and $\beta$-pinene $(17.8 \%)$. The adsorption of FM on the steel surface has been discussed according to the chemical composition of the oil, giving an explanation to the obtained results.
\end{abstract}

Keywords: fennel (Foeniculum vulgare), adsorption, corrosion, inhibition, carbon steel, hydrochloric acid.

\footnotetext{
* Corresponding author. E-mail address: hammoutib@gmail.com
} 


\section{Introduction}

The unforeseeable stops in the chain of industrial production due to corrosion become increasingly expensive and may cost billions of dollars each year for preventing and replacement of maintenance [1]. Then, the use of inhibitors is one of the most effective ways to prevent corrosion in various fields of application as acid pickling, industrial acid cleaning, acid descaling and oil well acidizing. Most of the efficient inhibitors are organic compounds that contain in their structures mostly nitrogen, sulphur or oxygen atoms. The organic corrosion inhibitors form protective film through the adsorption of their molecules on the metal surface while inorganic inhibitors act as cathodic and/or anodic inhibitors [2-4].

Recently, the use of some chemical inhibitors for corrosion prevention tends to be limited because of the environmental threat [5]. This has prompted, in several industrial sectors, the search for eco-friendly corrosion inhibitors for metals. Some of them are plant extracts, because they are environmentally acceptable, readily available and renewable source for a wide range of inhibitors needed. Plant extracts are incredibly rich sources of naturally synthesized chemical compounds (e.g. amino and organic acids, glucosinolates, alkaloids, polyphenols, tannins) and most are known to have inhibitive action. The uses of these natural products as corrosion inhibitors for different metals have been reported by several authors [6-10].

Raja and Sethuraman [11], in their review, give a synthesis on the use of natural products as anti-corrosion agents which are eco-friendly corrosion inhibitors. They become a source of cheap and environmental safe substances. A survey of the available literature in our laboratory indicates that natural extracts as well as essential oil from natural substances may play major role in the protection of metals against corrosion. We have proved that the use of herbs as extracts, oils or purified compounds can be used as new type of green inhibitors for acidic corrosion of steel. Menthols [12], artemisia [13], eugenol and acetyleugenol [14], rosemary oil [15], thyme [16], jojoba oil [17], ginger [18], bifurcaria bifurcata extract [19], etc., have been investigated.

Fennel (Foeniculum vulgare), member of the family of Apiaceae, grows wild in arid areas around Mediterranean Sea, and studies on the chemical composition of its essential oil are numerous in the literature [20-22].

The aim of this paper is to study the effect of fennel (Foeniculum vulgare) oil (FM) on the corrosion behaviour of carbon steel in hydrochloridric solution (1 M). Such FM oil effect is investigated using weight loss measurements, Tafel curves and AC impedance method. The corrosion inhibition mechanism is discussed based on the adsorption properties of FM oil on steel after immersion in the acidic medium.

\section{Experimental}

Carbon steel samples $(0.21 \% \mathrm{C}, 0.38 \% \mathrm{Si}, 0.09 \% \mathrm{P}, 0.01 \% \mathrm{Al}, 0.05 \% \mathrm{Mn}$, $0.05 \% \mathrm{~S}$ ) were used. Analytical grade $37 \% \mathrm{w} \mathrm{HCl}$ was used for the preparation of $1 \mathrm{M} \mathrm{HCl}$ by dilution with double distilled water. The inhibitory solution was prepared from the dissolution of the natural fennel (Foeniculum vulgare) oil, at various contents, in $1 \mathrm{M} \mathrm{HCl}$ solution. 
Electrochemical measurements were carried out in a conventional three electrode cylindrical glass cell. The working electrode (WE), in the form of a disc cut from steel, has a geometric area of $1 \mathrm{~cm}^{2}$. A saturated calomel electrode (SCE) and a platinum electrode were used as reference and auxiliary electrodes, respectively. The temperature was thermostatically controlled at $298 \mathrm{~K}$. Impedance measurements were carried out using AC signals of amplitude $10 \mathrm{mV}$ peak to peak at the open-circuit potential using Tacussel Radiometer PGZ 100 Frequency Response Analyser in a frequency range $100 \mathrm{kHz}$ to $1 \mathrm{mHz}$. The inhibition efficiency, $E(\%)$ was estimated from the measured charge-transfer resistance, $R_{\mathrm{ct}}$, values using the relation (1):

$$
E(\%)=\frac{1 / R_{\mathrm{ct}}^{0}-1 / R_{\mathrm{ct}}}{1 / R_{\mathrm{ct}}^{0}} \times 100
$$

where $R_{\text {ct }}^{0}$ and $R_{\mathrm{ct}}$ are the charge-transfer resistance values in the absence and presence of the inhibitor, respectively.

Polarisation curves were recorded using a potentiostat type Voltalab PGZ 100, at a scan rate of $30 \mathrm{mV} / \mathrm{min}$. The steel electrode was maintained at corrosion potential for $30 \mathrm{~min}$ and thereafter pre-polarised at $-800 \mathrm{mV}$ for $10 \mathrm{~min}$. The potential was swept to anodic potentials. All test solutions were de-aerated in the cell by using pure nitrogen for $30 \mathrm{~min}$ prior to the experiment. During each experiment, the test solution was mixed with a magnetic stirrer and the gas bubbling was maintained. In this case, the corrosion inhibition efficiency $(E \%)$ was determined according to the relation (2)

$$
\mathrm{E} \%=\left(1-\frac{\mathrm{I}_{\text {corr }}^{\prime}}{\mathrm{I}_{\text {corr }}}\right) \times 100
$$

where $I^{\prime}$ corr and $I_{\text {corr }}$ are the uninhibited and inhibited corrosion current densities, respectively, determined by extrapolation of cathodic Tafel lines to corrosion potential.

Gravimetric experiments were carried out for samples of steel of surface area of $5 \mathrm{~cm}^{2}$. These sheets were abraded successively with fine emery paper until 1200 grade. The sheets were then rinsed with distilled water, degreased and dried before being weighted and immersed in $60 \mathrm{~mL}$ of the corrosive medium. The immersion time was 6 hours at room temperature $(298 \mathrm{~K})$ in air without bubbling in a double walled glass cell equipped with a thermostat-cooling condenser. Each value is the mean of triplicate experiences. The inhibition efficiencies $(E \%)$ were calculated using relation (3)

$$
E(\%)=\frac{W_{\text {corr }}^{0}-W_{\text {corr }}}{W_{\text {corr }}^{0}} \times 100
$$

where $W_{\text {corr }}$ and $W_{\text {corr }}^{0}$ are the corrosion rates of steel samples with and without inhibitor, respectively. 


\section{Hydro-distillation apparatus and procedure}

Samples of fennel (Foeniculum vulgare) were collected in February 2010 from fields around the area of Swanni located in AlHoceima region (Morocco). The dried aerial parts were submitted to hydro-distillation for $4 \mathrm{~h}$ using a Clevengertype apparatus according to the European Pharmacopoeia and yielded $1.4 \%$ of oil. The oil was collected, dried under anhydrous sodium sulphate and stored at 4 ${ }^{\circ} \mathrm{C}$ until used.

\section{Gas Chromatography (GC) Analysis}

GC analyses were carried out using a Perkin Elmer Clarus 600 fast GC apparatus equipped with a single injector and two flame ionization detectors (FID). The apparatus was used for simultaneous sampling to two fused-silica capillary columns $(60 \mathrm{~m} \times 0.22 \mathrm{~mm}$, film thickness $0.25 \mu \mathrm{m})$ with different stationary phases: Rtx-1 (polydimethylsiloxane) and Rtx-Wax (polyethylene glycol). Temperature program: the oven temperature was programmed from 60 to $230{ }^{\circ} \mathrm{C}$ at $2{ }^{\circ} \mathrm{C} / \mathrm{min}$ and then held isothermally at $230{ }^{\circ} \mathrm{C}(35 \mathrm{~min})$. Carrier gas: He (1 $\mathrm{mL} / \mathrm{min})$. Injector and detector temperatures were held at $280{ }^{\circ} \mathrm{C}$. Split injection was conducted with a ratio split of 1:50. Retention indices $(I)$ of compounds were determined relative to the retention times of series of $n$-alkanes $\left(\mathrm{C}_{5}-\mathrm{C}_{30}\right)$ with linear interpolation, using Van den Dool and Kratz equation and software from Perkin-Elmer. Relative component concentrations were calculated based on GC peak areas without using correction factors.

\section{Gas Chromatography-Mass Spectrometry (GC/MS)}

Oil and all collected fractions were analyzed using a Perkin Elmer Turbo Mass detector, directly coupled to a Perkin Elmer Autosystem XL equipped with two fused-silica capillary columns $(60 \mathrm{~m} \times 0.22 \mathrm{~mm}$, film thickness $0.25 \mu \mathrm{m}), \mathrm{Rtx}-1$ (polydimethylsiloxane) and Rtx-Wax (polyethylene glycol). GC conditions were the same as described in GC analysis section. Ion source temperature: $150{ }^{\circ} \mathrm{C}$; energy ionization: $70 \mathrm{eV}$; electron ionization mass spectra were acquired over the mass range 35-350 Da. Oil injected volume: $0.1 \mu \mathrm{L}$; fractions injected volume: $0.2 \mu \mathrm{L}$.

\section{Components identification}

Identification of the components was based firstly on the comparison of their GC retention indices (RI) on non polar and polar columns, determined according to the retention time of a series of n-alkanes with linear interpolation, with those of authentic compounds or literature data; and secondly on computer matching with commercial mass spectral libraries [23-26] and comparison of spectra with those of our personal library. Relative amounts of individual components were performed on the basis of their GC peak areas on the two capillary Rtx-1 and Rtx-Wax columns, without FID response factor correction. 


\section{Results and discussion}

\section{Corrosion tests}

The impedance diagrams (Fig. 1) show the corrosion behaviour observed after 30 min of immersion of the steel electrode in the absence and presence of FM oil at various contents at $298 \mathrm{~K}$. The impedance parameters, such as charge transfer resistance $\left(R_{\mathrm{ct}}\right)$, maximum frequency $\left(f_{\max }\right)$ and double layer capacitance $\left(C_{\mathrm{dl}}\right)$, are derived from these investigations and listed in Table 1 . The impedance diagrams (Fig. 1) show semi-circles indicating that charge transfer processes are mainly controlling the corrosion of steel. The charge transfer resistance $\left(R_{\mathrm{ct}}\right)$ values are calculated from the difference in impedance at lower and higher frequencies. The double layer capacitance $\left(C_{\mathrm{dl}}\right)$ and the frequency at which the imaginary component of the impedance is maximal $\left(-Z_{\max }\right)$ are found as represented in equation (4)

$$
C_{d l}=\frac{1}{2 \pi f_{\max } R_{c t}}
$$

The inhibition efficiency is calculated from the charge-transfer resistance according to equation (1).

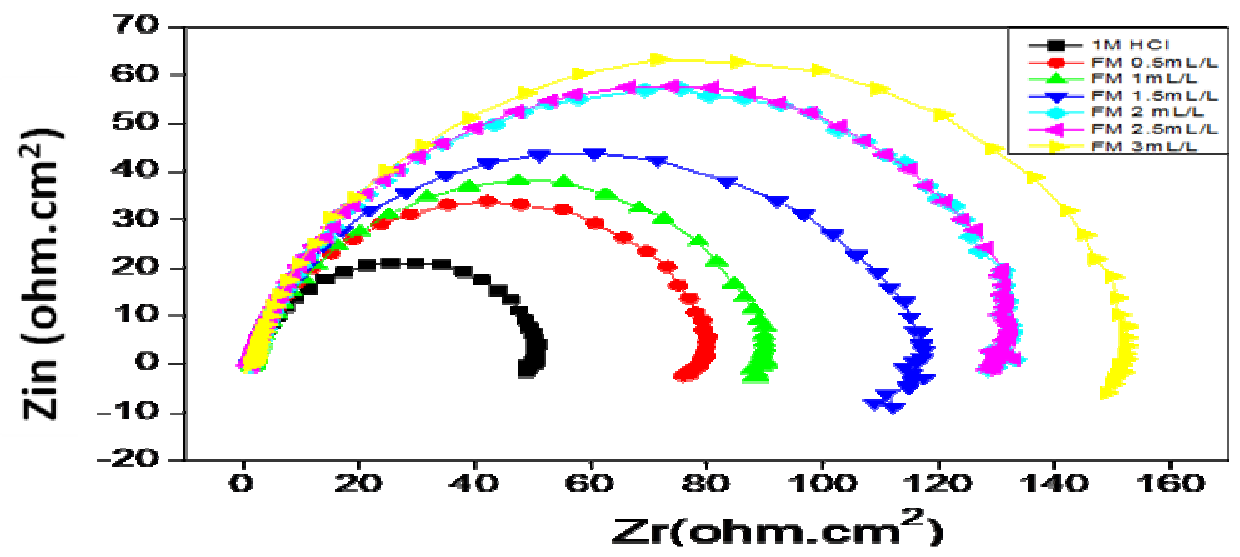

Figure 1. Nyquist diagrams of steel samples after immersion in $1 \mathrm{M} \mathrm{HCl}$ in the absence and presence of FM oil at various concentrations.

Table 1. EIS parameters of steel samples after immersion in $1 \mathrm{M} \mathrm{HCl}$ in the absence and presence of FM oil at various concentrations.

\begin{tabular}{|c||c|c||c||c|}
\hline$[\mathrm{FM}]=\mathrm{mL} / \mathrm{L}$ & $R_{\mathrm{ct}} /\left(\Omega . \mathrm{cm}^{2}\right)$ & $f_{\mathrm{max}} / \mathrm{Hz}$ & $C_{\mathrm{dl}} /\left(\mu \mathrm{F} . \mathrm{cm}^{-2}\right)$ & $E /(\%)$ \\
\hline $\mathrm{HCl}$ & 49 & 63 & 119 & ---- \\
\hline 0.5 & 80 & 63 & 74 & 38 \\
\hline 1 & 87 & 40 & 105 & 44 \\
\hline 1.5 & 113 & 63 & 56 & 57 \\
\hline 2 & 131 & 22 & 125 & 63 \\
\hline 2.5 & 152 & 40 & 63 & 68 \\
\hline 3 & 203 & 31 & 63 & 76 \\
\hline
\end{tabular}


The impedance response of the steel in acid solution has significantly changed after addition of FM oil, and the impedance increases with increasing FM content. In fact, the presence of FM oil enhances the value of $\mathrm{R}_{\mathrm{ct}}$ in acidic solution. The values of double layer capacitance are also brought down to the maximum extent in the presence of the inhibitor. The decrease in $C_{\mathrm{dl}}$ values is due to the adsorption of FM oil components on the metal surface leading to the formation of a film which limits the corrosive effect of the acidic solution [27]. We also note an increase in the corrosion inhibition efficiency due to the increase of $R_{\mathrm{ct}}$ values with the concentration of the inhibitor.

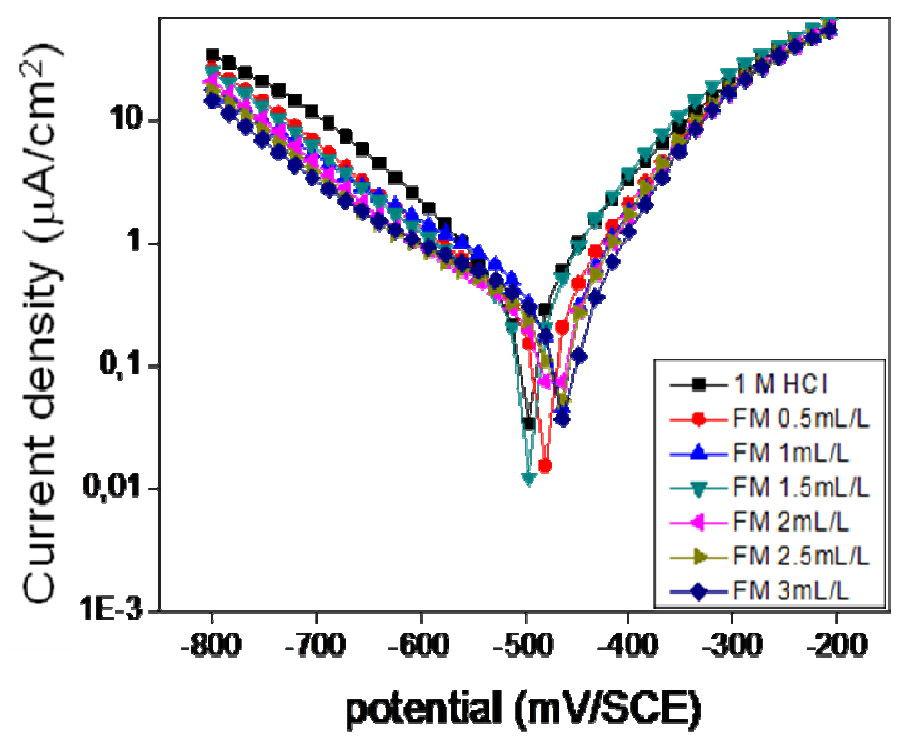

Figure 2. Polarisation curves of steel samples after immersion in $1 \mathrm{M} \mathrm{HCl}$ in the absence and presence of FM oil at various concentrations at $298 \mathrm{~K}$.

Polarisation curves of steel samples after immersion in $1 \mathrm{M} \mathrm{HCl}$ in the absence and presence of FM oil at various concentrations are presented in Fig. 2. As expected, the polarisation curves of the steel were considerably modified when FM oil is added. Indeed, both cathodic and anodic reactions of carbon steel electrode corrosion were inhibited with the increase of FM oil content. This result suggests that FM oil addition reduces anodic dissolution and also retards the hydrogen evolution reaction. The values of associated electrochemical parameters such as corrosion potential $\left(E_{\text {corr }}\right)$, corrosion current density $\left(I_{\text {corr }}\right)$ and cathodic Tafel slopes $\left(b_{c}\right)$, obtained by extrapolation of the Tafel lines are presented in Table 2. It is seen that FM oil addition decreases $I_{\text {corr }}$ significantly. Also a slight decrease of the corrosion potential to more negative values in the presence of the inhibitor is explained by the catalytic action of naturally oil on anodic branches. We may conclude that the oil acts as a mixed type inhibitor. The adsorption of oil molecules on the metal surface forms a barrier that hinders the access of hydrogen ions to the steel surface and then their reduction on the cathodic sites which can significantly improve the corrosion characteristics. FM oil addition modifies slightly the value of $b_{c}$, showing that the steel surface is modified when FM oil is present in the aggressive medium. On the other hand, 
the cathodic current vs. potential curves gave rise to parallel Tafel lines, indicating that the hydrogen evolution reaction is activation controlled, and the adsorption of FM oil does not modify the mechanism of the proton discharge reaction. Moreover, the inhibition efficiency $E(\%)$ calculated using $I_{\text {corr }}$, following Eq. (2), increases with oil concentration to attain $77 \%$ at $3 \mathrm{~mL} / \mathrm{L}$.

Table 2. Electrochemical parameters of steel samples after immersion in $1 \mathrm{M} \mathrm{HCl}$ in the absence and presence of FM oil at various concentrations.

\begin{tabular}{|c|c|c|c|c|c|}
\hline Inhibitor & $\begin{array}{c}\text { Concentration } / \\
(\mathrm{mL} / \mathrm{L})\end{array}$ & $\begin{array}{c}E_{\text {corr }} / \\
(\mathrm{mV} / \mathrm{SCE})\end{array}$ & $\begin{array}{c}b_{\mathrm{c}} / \\
(\mathrm{mV} / \mathrm{dec})\end{array}$ & $\begin{array}{c}I_{\text {corr }} / \\
\left(\mu \mathrm{A} / \mathrm{cm}^{2}\right)\end{array}$ & $\begin{array}{c}E\rfloor \\
(\%)\end{array}$ \\
\hline \multirow{5}{*}{ FM oil } & 0 & -500 & 110 & 698 & - \\
\cline { 2 - 6 } & 0.5 & -499 & 67 & 412 & 41 \\
\cline { 2 - 6 } & 1 & -498 & 59 & 388 & 44 \\
\cline { 2 - 6 } & 1.5 & -487 & 48 & 325 & 53 \\
\cline { 2 - 6 } & 2 & -484 & 72 & 307 & 56 \\
\cline { 2 - 6 } & 2.5 & -484 & 62 & 175 & 75 \\
\hline
\end{tabular}

Corrosion rates of steel samples were determined in aerated $1 \mathrm{M} \mathrm{HCl}$ solution at various contents of FM oil for 6 hours of immersion at $298 \mathrm{~K}$. Table 3 shows the values of inhibition efficiencies and corrosion rates obtained from mass loss method at different inhibitor concentrations. The corrosion rate is found to decrease with the FM oil's concentration. These data indicate clearly that natural oil exhibits an inhibitive effect on the corrosion of steel in $1 \mathrm{M} \mathrm{HCl}$. A maximum of inhibition efficiency in these conditions $(73 \%)$ is obtained at $3 \mathrm{~mL} / \mathrm{L}$.

Table 3. Gravimetric results for carbon steel after $6 \mathrm{~h}$ of immersion period in $1 \mathrm{M} \mathrm{HCl}$ containing various contents of FM oil at $298 \mathrm{~K}$.

\begin{tabular}{|c|c|c|c|}
\hline Inhibitor & Concentration & $W_{\text {corr }} /\left(\mathrm{mg} / \mathrm{cm}^{2} . \mathrm{h}\right)$ & $E /(\%)$ \\
\hline $\mathrm{HCl}$ & $1 \mathrm{M}$ & 0.32 & - \\
\hline \multirow{4}{*}{$\mathrm{FM}$ oil } & $0.5 \mathrm{~mL} / \mathrm{L}$ & 0.20 & 38 \\
\cline { 2 - 4 } & $1 \mathrm{~mL} / \mathrm{L}$ & 0.19 & 41 \\
\cline { 2 - 4 } & $1.5 \mathrm{~mL} / \mathrm{L}$ & 0.14 & 56 \\
\cline { 2 - 4 } & $2 \mathrm{~mL} / \mathrm{L}$ & 0.13 & 59 \\
\cline { 2 - 4 } & $2.5 \mathrm{~mL} / \mathrm{L}$ & 0.12 & 63 \\
\cline { 2 - 4 } & $3 \mathrm{~mL} / \mathrm{L}$ & 0.09 & 73 \\
\hline
\end{tabular}

A comparison may be made between inhibition efficiency $E(\%)$ values obtained by different methods (weight loss, polarization curves and EIS methods). Fig. 3 shows a histogram that compares the $E(\%)$ values obtained. One can see that whatever the method used, no significant changes are observed in $E(\%)$ values. We can then conclude that there is a good correlation with the three methods used in this investigation at all tested concentrations and that FM oil is an efficient corrosion inhibitor. 


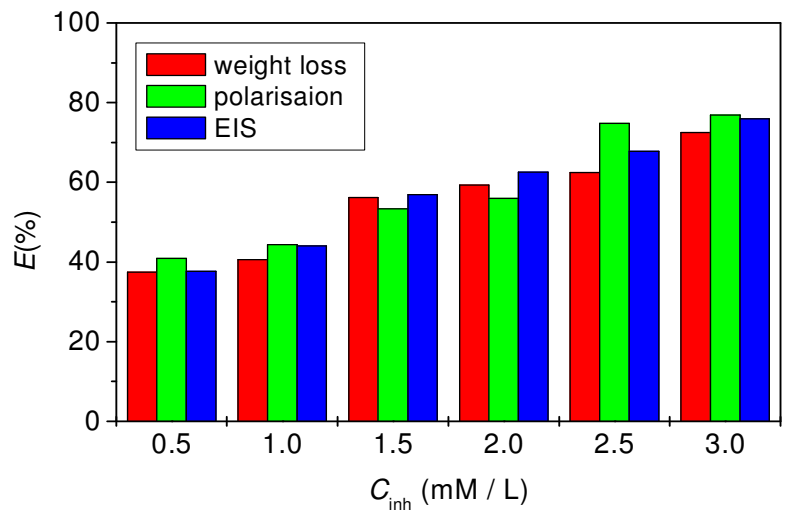

Figure 3. Comparison of inhibition efficiency (E\%) values obtained by weight loss, polarization and EIS methods.

The influence of temperature on the corrosion behaviour of steel in acidic medium was also studied in the absence and presence of fennel (Foeniculum vulgare) oil between 313 and $343 \mathrm{~K}$ at $1 \mathrm{~h}$ using weight loss measurements (Table 4).

The corrosion rate of steel increases with temperature both in the absence and presence of the inhibitor at a maximal concentration $(3 \mathrm{~mL} / \mathrm{L})$. The presence of inhibitor leads to a decrease of the corrosion rate. The increase in corrosion rate is more pronounced with the rise of temperature and the apparent activation energy is calculated according to equations (5)

$$
W_{\text {corr }}=k \exp \left(\frac{-E_{a}}{R T}\right) \quad \text { and } \quad W_{c o r r}^{\prime}=k^{\prime} \exp \left(\frac{-E_{a}^{\prime}}{R T}\right)
$$

where $\mathrm{W}^{\prime}$ corr and $\mathrm{W}_{\text {corr }}$ are the corrosion rates of steel with and without fennel (Foeniculum vulgare) oil, respectively. $E^{\prime}{ }_{a}$ and $E_{a}$ are the apparent activation energies with and without inhibitor, respectively.

Table 4. Effect of temperature on the corrosion rates of steel in the absence and presence of FM oil ( $3 \mathrm{~mL} / \mathrm{L})$ after $1 \mathrm{~h}$ of immersion.

\begin{tabular}{|c|c|c|c|}
\hline $\mathrm{T} /(\mathrm{K})$ & $\begin{array}{c}W_{\text {corr }} / \\
\left(\mathrm{mg} / \mathrm{cm}^{2} \mathrm{~h}\right)\end{array}$ & $\begin{array}{c}W_{\text {corr }}^{\prime} / \\
\left(\mathrm{mg} / \mathrm{cm}^{2} \mathrm{~h}\right)\end{array}$ & $\begin{array}{c}E / \\
(\%)\end{array}$ \\
\hline 313 & 1.65 & 0.27 & 83 \\
\hline 323 & 3.24 & 0.92 & 72 \\
\hline 333 & 5.40 & 1.84 & 66 \\
\hline 343 & 11.02 & 3.70 & 66 \\
\hline
\end{tabular}

Straight lines of Arrhenius law permit the evaluation of activation energies from the corresponding slopes (Fig. 4). Values obtained of activation energies are $E_{\mathrm{a}}=$ 55.36 and $E^{\prime}{ }_{a}=76.53 \mathrm{~kJ} / \mathrm{mol}$, respectively. It is clear that the addition of inhibitor provokes an increase in the values of apparent activation energy. Popova et al. [28] pointed out that the decrease of E\% may be attributed to the 
specific interaction between the iron surface and the inhibitor components. The higher value of activation energy $E_{a}$ of the corrosion process, when FM oil is added, when compared to activation energy value $E_{a}$ for the medium without inhibitor, is attributed to an electrostatic adsorption mechanism of the inhibitor [28-30].

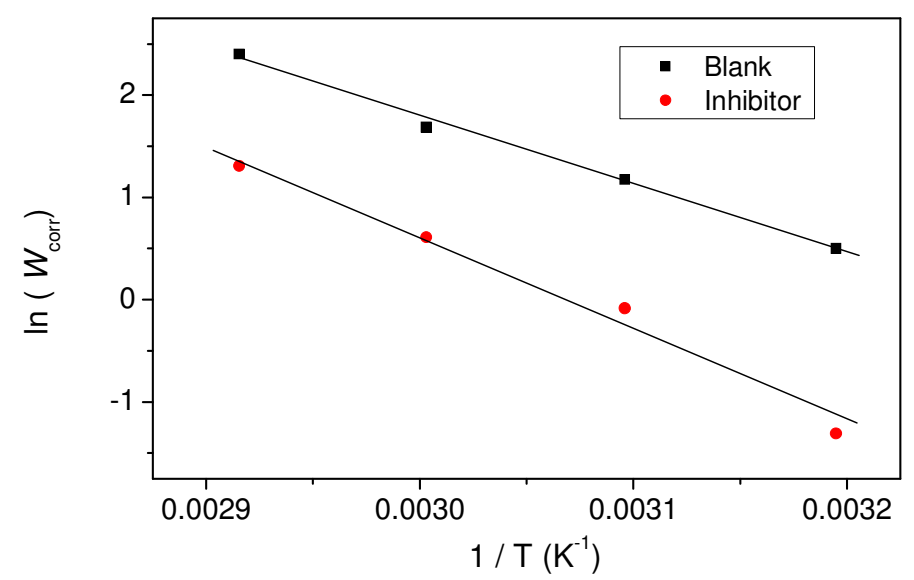

Figure 4. Arrhenius plots of corrosion rates of steel in the absence and presence of FM oil $(3 \mathrm{~mL} / \mathrm{L})$ after $1 \mathrm{~h}$ of immersion.

In order to identify the composition of FM oil and to characterize organic compounds responsible for the corrosion inhibition, the analysis of FM oil using GC/FID and GC/MS was carried out. The composition of FM oil was variable according to the area of harvest and the stage of development. The analysis allowed the identification of 21 components which accounted for $96.6 \%$ of the total weight. Their retention indices and their relative percentages are reported in Table 5. The main constituents were limonene $(20.8 \%)$ and $\beta$-pinene $(17.8 \%)$ (Fig. 5), followed by myrcene (15\%) and fenchone (12.5\%). The adsorption of these molecules could take place via interaction with the vacant $\mathrm{d}$-orbitals of iron atoms (chemisorption). It is logical to assume that such adsorption is mainly responsible for the good protective properties of these compounds. We may easily introduce that inhibition occurs by a synergistic effect of this various molecules [29,31-32].<smiles>C=C(C)C1CC=C(C)CC1</smiles><smiles>C=C1CCC2CC1CC21CCCCC1</smiles>

Figure 5. Molecular structures of limonene and $\beta$-pinene. 
Table 5. Chemical composition of fennel (Foeniculum vulgare) essential oil.

\begin{tabular}{|c|c|c|c|c|}
\hline Compounds & I l & I $a$ & $I p$ & $\%$ \\
\hline a-Thujene & 932 & 922 & 1012 & 0,1 \\
\hline a-Pinene & 936 & 930 & 1012 & 8 \\
\hline Sabinene & 973 & 965 & 1109 & 1 \\
\hline b-Pinene & 978 & 972 & 1099 & 17.8 \\
\hline Myrcene & 987 & 981 & 1150 & 15 \\
\hline a-Phellandrene & 1002 & 1000 & 1150 & 0.3 \\
\hline 3-Carene & 1010 & 1006 & 1132 & 0.7 \\
\hline p-Cymene & 1015 & 1013 & 1250 & 1.5 \\
\hline Limonene & 1025 & 1022 & 1193 & 20.8 \\
\hline b-Phellandrene & 1023 & 1022 & 1193 & \\
\hline g-Terpinene & 1051 & 1048 & 1226 & 0.8 \\
\hline trans-hydrate-Sabinene & 1053 & 1052 & 1441 & \\
\hline Fenchone & 1069 & 1067 & 1386 & 12.5 \\
\hline Terpinolene & 1082 & 1078 & 1262 & 2.4 \\
\hline Linalol & 1086 & 1083 & 1522 & 0,3 \\
\hline Isovalerate 3-methylbutyl & & 1088 & 1277 & \\
\hline Camphre & 1123 & 1115 & 1494 & 0.1 \\
\hline trans-Pinocarveol & 1126 & 1122 & 1633 & 0.2 \\
\hline Cryptone & 1160 & 1154 & 1665 & \\
\hline p-Cymene-8-ol & 1169 & 1155 & 1815 & \\
\hline Terpinen-4-ol & 1164 & 1160 & 1573 & 0.4 \\
\hline a-Terpineol & 1176 & 1167 & 1674 & 0.3 \\
\hline Isoascaridole & 1295 & 1290 & 1850 & \\
\hline Piperitenone & 1318 & 1308 & 1880 & 1 \\
\hline Piperitenone oxyde & 1335 & 1331 & 1910 & 12.5 \\
\hline Geranyl acetate & 1362 & 1361 & 1732 & 0.2 \\
\hline Nepetalactone & & 1374 & 1955 & 0.7 \\
\hline \multicolumn{2}{|c|}{ Total } & & & $96.6 \%$ \\
\hline
\end{tabular}

Hydrocarbon compounds

$8.9 \%$

Oxygenated compounds $\quad 77.1 \%$

Hydrocarbon monoterpenes $\quad 8.9 \%$

Oxygenated monoterpenes $\quad 76.8 \%$

Hydrocarbon sesquiterpenes $\quad 0 \%$

Oxygenated sesquiterpenes $0.3 \%$

$I l:$ Retention indices on the apolar column from literature except those with *.

I $a$, I $p$ : Retention indices on the apolar Rtx-1 column and on the polar Rtx-Wax, respectively.

All compounds have been identified by GC(RI) and GC-MS from our laboratory library.

\section{Conclusion}

From the overall experimental results the following conclusions can be deduced:

1. The major constituents of fennel (Foeniculum vulgare) oil (FM) are limonene $(20.8 \%)$ and $\beta$-pinene (17.8\%).

2. Fennel (Foeniculum vulgare) oil provides a good inhibition of corrosion of carbon steel in normal hydrochloric acid medium. 
3. The inhibition efficiency increases with the concentration of fennel (Foeniculum vulgare) oil.

\section{References}

1. P.R. Roberge, Corrosion Engineering Principles and Practice, McGrawHill, 2008, p. 19.

2. A.Y. El-Etre, Appl. Surf. Sci.252 (2006) 8521. 10.1016/j.apsusc.2005.11.066

3. K.O. Orubite, N.C. Oforka, Mater. Lett. $58 \quad$ (2004) 1768. 10.1016/j.matlet.2003.11.030

4. G.O. Avwiri, F.O. Igho, Mater. Lett. 57 (2001) 3705. 10.1016/S0167577X(03)00167-8

5. A.M. Abdel-Gaber, E. Khamis, H. Abo-ElDahab, Sh. Adeel, Mater. Chem. Phys. 109 (2008) 297. 10.1016/j.matchemphys.2007.11.038

6. A. Lecante, F. Robert, P.A. Blandinières, C. Roos, Curr. Appl. Phys. 11 (2011) 714. 10.1016/j.cap.2010.11.038

7. G. Matamala, W. Smeltzer, G. Droguett, Corros. Sci. 42 (2000) 1351. 10.1016/S0010-938X(99)00137-7

8. A.Y. El-Etre, Corros. Sci. 40 (1998) 1845. 10.1016/S0010-938X(98)000821

9. H. Al-Sehaibani, Mater Wissen Werkst Tech. 31 (2000) 1060. 10.1002/1521-4052(200012)31:12<1060::AID-MAWE1060>3.0.CO;2-K

10. P.B. Raja, M.G. Sethuraman, Corros. Eng. Sci. Tech. 45 (2010) 455-460. 10.1179/147842208X388762

11. P.B. Raja, M.G. Sethuraman, Mater. Lett. $62 \quad$ (2008) 113. 10.1016/j.matlet.2007.04.079

12. Z. Faska, L. Majidi, R. Fihi, A. Bouyanzer, B. Hammouti, Pigm. Resin Techn. 36 (2007) 293. 10.1108/03699420710820405

13. M. Benabdellah, B. Hammouti, M. Benkaddour, M. Bendahhou, A. Aouniti, Appl. Surf. Sci. 252 (2006) 6212. 10.1016/j.apsusc. 2005.08 .030

14. E. Chaieb, A. Bouyanzer, B. Hammouti, M. Benkaddour, Appl. Surf. Sci. 246 (2005) 199. 10.1016/j.apsusc.2004.11.011

15. A. Chetouani, B. Hammouti, M. Benkaddour, Pigm. Resin Techn. 33 (2004) 26. $10.1108 / 03699420410512077$

16. A. Bouyanzer, B. Hammouti, Bull. Electrochem. 20 (2004) 63.

17. A. Bouyanzer, B. Hammouti, Pigm. Resin Techn. 33 (2004) 287. 10.1108/03699420410560489

18. A. Chetouani, B. Hammouti, Bull. Electrochem. 19 (2003) 23.

19. Y. Abboud, A. Abourriche, T. Ainane, M. Charrouf, A. Bennamara, O. Tanane, B. Hammouti, Chem. Eng. Comm. 196 (2009) 788. 10.1080/00986440802589875

20. A. Ouyahya, R. Negre, J. Viano, Y.F. Lozano, E.M. Gaydou, Wiss. u.Technol. 23 (1990) 528-530. 
21. G. Vernin, O. Merad, G.M.F. Vernin, R.M. Zamkotsian, C. Párkányi, In: G. Charalambous, Editor, Food Flavors: Generation, Analysis and Process Influence, Elsevier Science BV, Amsterdam (1995), pp. 147-205

22. S. Salido, L.R. Valenzuela, J. Altarejos, M. Nogueras, A. Sánchez, E. Cano, Biochem. Syst. Ecol. 32 (2001) 265. 10.1016/j.bse.2003.09.002

23. W.A. König, D.H. Hochmuth, D. Joulain, Library of Mass Finder 2.1, Institute of Organic Chemistry, Hamburg, Germany, 2001.

24. National Institute of Standards and Technology. NIST WebBook (06/2005): http://webbook.nist.gov/chemistry.

25. F.W. McLafferty, D.B. Stauffer, Wiley Registry of Mass Spectral Data, 6th edn. Mass Spectrometry Library Search System Bench-Top/PBM, version 3.10d. Palisade: Newfield, 1994.

26. R.P. Adams, Identification of essential oil Components by Gaz Chromatography /Mass Spectroscopy. Allured: Carol Stream, IL, 1995.

27. B. Zerga, M. Sfaira, Z. Rais, M. Ebn Touhami, M. Taleb, B. Hammouti, B. Imelouane, A. Elbachiri, Materiaux et Techniques 97 (2009) 297. 10.1051/mattech/2009045

28. A. Popova, E. Sokolova, S. Raicheva, M. Christov, Corros. Sci. 45 (2003) 33. 10.1016/S0010-938X(02)00072-0

29. A. Zarrouk, I. Warad, B. Hammouti, A. Dafali, S.S. Al-Deyab, N. Benchat, Int. J. Electrochem. Sci. 5 (2010) 1516.

30. M. Dahmani, A. Et-Touhami, S.S. Al-Deyab, B. Hammouti, A. Bouyanzer, Int. J. Electrochem. Sci. 5 (2010) 1060.

31. I. Naqvi, A.R. Saleemi, S. Naveed, Int. J. Electrochem. Sci. 6 (2011) 146161.

32. M. Znini, M. Bouklah, L. Majidi, S. Kharchouf, A. Aouniti, A. Bouyanzer, B. Hammouti, J. Costa, S.S. Al-Deyab, Int. J. Electrochem. Sci. 6 (2011) 691. 